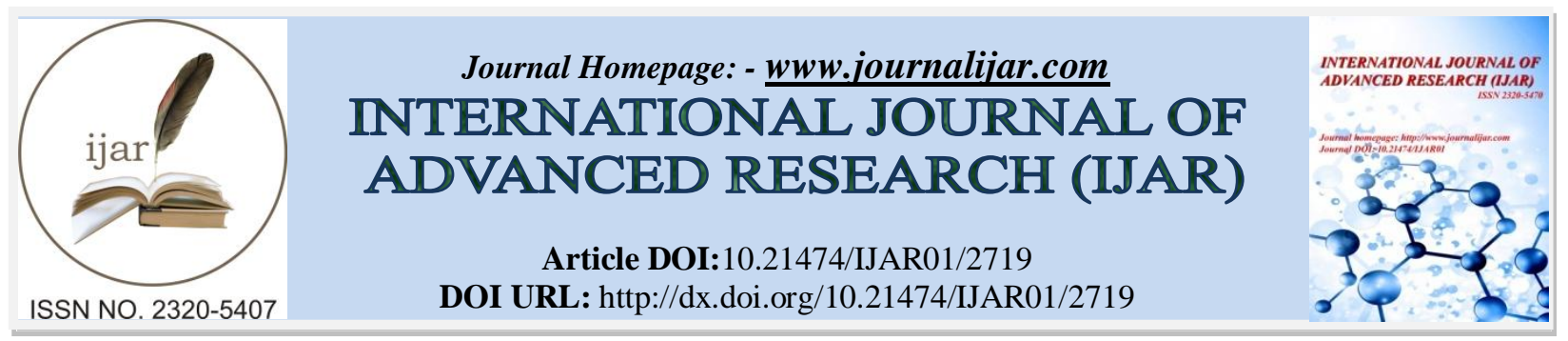

RESEARCH ARTICLE

\title{
AUTOGENOUS VERSUS COMPOSITE GRAFT FOR THE AUGMENTATION OF ANTERIOR MAXILLA PRIOR TO IMPLANT PLACEMENT - A COMPARATIVE STUDY.
}

\section{Dr. JADHAV PRANAVI, Dr. DHUSHYANTH PAUL, Dr. ANMOL AGARWAL}

\section{Manuscript Info}

Manuscript History

Received: 15 November 2016

Final Accepted: 17 December 2016

Published: January 2017

Key words:-

Augmentation, Atrophic

maxilla,Autograft,Composite graft,

Implant.

\section{Abstract}

Aim:To evaluate the efficacy of autogenous and composite graft in anterior maxilla for implant placement.

Material and methods: A prospective, double blinded, randomised controlled study was conducted among 10 subjects between 2014 and 2015 who sustained injury due to road traffic accident associated with avulsion of anterior maxillary teeth and loss of labial cortical bone. These subjects were randomly categorized into two groups. Group A consisted of 5 subjects in whom autogenous chin graft was used to augment anterior maxilla while in Group B having another 5 subjects, composite graft (mixture ofcrushed alveolar bone andallograft - $\mathrm{Bi}$ Oss powder) was used. All the patients were evaluated clinically for donor and recipient site morbidity, healing of soft tissue, and amount of bone formed with resorption pattern radiographically.

Results: There was no significant recipient site morbidity found in Group B, whereas in Group A all subjects manifested with mild swelling and pain (Visual analog sale score $>3$ on $10 \mathrm{~cm}$ scale) and 1 subject has mild paresthesia of lower lip for few weeks.

Conclusion: Both the types of grafts used for augmentation of anterior maxilla prior to implant placement presented with the same amount of bone formation, graft resorption and healing of soft tissues. However, there was a difference noticed in recipient site morbidity and torque obtained which was in favour of using a composite graft.

Copy Right, IJAR, 2016,. All rights reserved.

\section{Introduction:-}

Alveolar bone resorption secondary to extraction or loss of tooth is a natural phenomenon. Intensity of resorption is greater in the cases with traumatic loss of the tooth especially maxillary anterior teeth which is usually associated with the loss of labial cortical bone as well. Such patients seeking for the replacement of their missing teeth, wish to choose an option which is next to natural. Dental implants over a period of last two decades have shown promising results in this field but in most of these casesclinicians encounter inadequate width and depth of the bone requiredfor the successful placement of a dental implant. Normally also when it comes to the replacement of teeth in maxilla, it presents with a cancellous and D3 type of bone density, amount of resorption is also high especially in the maxillary anterior region, which is of more aesthetic concern to the patient. In patients with history of traumatic tooth loss especially in anterior maxilla, the situation is even worst. Initial stabilization of an implant is quite difficult to achieve in such cases. ${ }^{1,2}$ 
The present study was conducted to weigh merits and demerits of autograft over composite graft in 10 subjects who reported to our unit seeking replacement of missing teeth in anterior maxilla with dental implants.

\section{Materials and Methods:-}

A prospective randomised study conducted in 10 subjects with history of loss of maxillary anterior teeth due to road traffic accident reported to our unit for rehabilitation with dental implant. Their age ranged between 24-32years and were randomly categorized into Group A and Group B. In Group A, alveolar augmentation was done using autogenous chin block graft while in Group B augmentation was performed using composite particulate graft (mixture of alveolar bone and allograft - Bio-Oss). The parameters evaluated were ease of implant placement, pain, paraesthesia, vitality of associated teeth, cost, amount of bone formed, graft resorption 3months postoperatively.

\section{Surgical technique:-}

The surgical procedure was performed in sterile surgical field and after obtaining adequate anaesthesia. In Group Apatients, for harvesting the graft a vestibular incision extending from mandibular first premolar on either side was given and mucoperiosteal flap is reflected. Piezo-osteotome was used to make osteotomy cuts following Rule of 5 i.e.maintaining $5 \mathrm{~mm}$ safety margin from mental foramen on both sides, $5 \mathrm{~mm}$ below apices of teeth and $5 \mathrm{~mm}$ above lower border of mandible as shown in Figure $01 .{ }^{3}$ The recipient site is exposed using a crestal incision and the harvested graft was placed followed by fixation using Titanium screw, perforations were made in the recipient site to induce bleeding and allow rapid take-up of the graft. After 3months Titanium screws were removed and implant was placed.In Group B after exposing the recipient site, autograft was collected by nibbling or scrapping the adjacent alveolar bone which was then mixed with the allograft. This prepared composite graft is then positioned and secured with a collagen membrane and closure was done.

\section{Results:-}

Among 10 subjects included in the study were randomly categorized into 2 groups. Group A in which autograft was used for augmentation, and Group B where composite graft (Alveolar graft mixed with Bio-Oss and Biomembrane) was used. Demographic data in both the groups was comparable. Mean age in Group A was 27.8 and in Group B 28.2 with no statistical significance. Etiology for loss of teeth in all individuals was road traffic accident involving anterior maxillary alveolus. Amount of bone was measured clinically and radiographically before and after augmentation. Preoperatively the mean available bone when measured clinically was $2-3 \mathrm{~mm}$ (mean $2.6 \mathrm{~mm}$ ) and when measured radiographically using CBCT was $2-3 \mathrm{~mm}$ (mean $2.2 \mathrm{~mm}$ ) in both the groups. 3months postoperatively the amount of bone available was $8-10 \mathrm{~mm}$ (mean 2.6)in group A and 6-8mm (mean $2.2 \mathrm{~mm}$ ) in group B which may be attributed to the more amount of autogenous bone harvested.

Obtaining alveolar bone mixing with Bio-Oss and Biomembrane was comparatively easily as it consumed less time, machine and manpower. Whereas, Autogenous graft obtained required Piezo-osteotome, consumed time and associated with postoperative morbidity at donor site. Therefore, the need to develop an allograft, alloplast, or xenograft substitute is widely recognized. ${ }^{4}$

To utilise properties of both autograft and allograft we have preferred using composite graft (Alveolar bone along with Bio-Oss and Biomembrane) as a graft material. Bioss andBiomembrane aids in formation of new bone as stated by Banwart JC etal. ${ }^{5}$ After 3 months the recipient site was evaluated for amount of bone formed. Adequate bone height and width is formedclinically with mean of $8.8 \mathrm{~mm}$ and radiographically mean of $8.8 \mathrm{~mm}$ in Group A. In group Bmean bone formed was $7.2 \mathrm{~mm}$ clinically and $6.8 \mathrm{~mm}$ radiographically. There was statistically significant difference in both groups clinically and radiographically $0.05 \mathrm{~mm}$ and $0.02 \mathrm{~mm}$ respectively as shown in Table 02.Implants were placed after 4monthsMean torque obtained was $38 \mathrm{~mm}$ and $33 \mathrm{~mm}$ in group A and B respectively which was statistically significant (p 0.02) as shown in Table 03 .

In all subjects there was ease in placement of implant. Postoperative swelling was measured both at recipient site and donor site $24^{\text {th }}, 48^{\text {th }}$ and 1 week duration. Postoperative swelling at recipient site was not statistically significant in both groups $(0.072)$. There was no difference on $24^{\text {th }} \mathrm{hr}$ and 1 week postoperatively. However on $48^{\text {th }} \mathrm{hr}$ statistically significant difference in postoperative swelling at donor site was seen. (P- 0.011) In both the groups implants were placed successfully after 3 months of grafting. Postoperative paraesthesia was measured at both donor and recipient site. Amongst all 10 subjects one among them reported with mild paraesthesia for few weeks at recipient where block graft from chin was harvested for few weeks which was not statistically significant. (P 
0.317).Postoperative pain at donor and recipient site was also not significant in either of the groups (P 0.134).Healing of soft tissue in either sites and groups was uneventful. (Table 01).

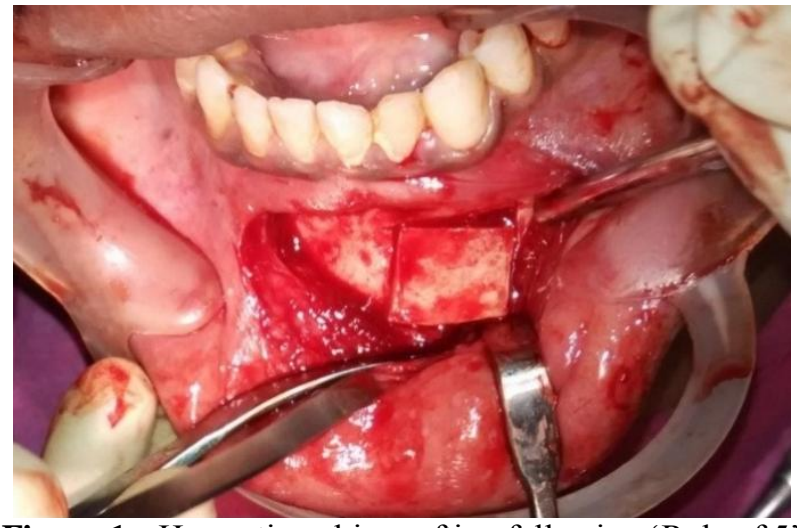

Figure 1:- Harvesting chin grafting following 'Rule of 5 '

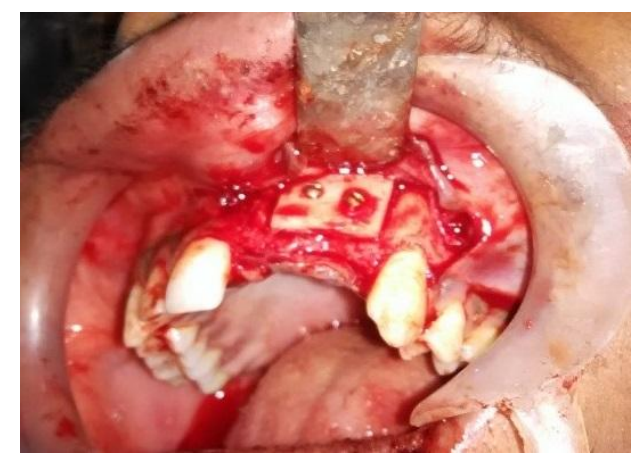

Figure 2:- Preparation of recipient site and fixation of graft using Titanium screw.

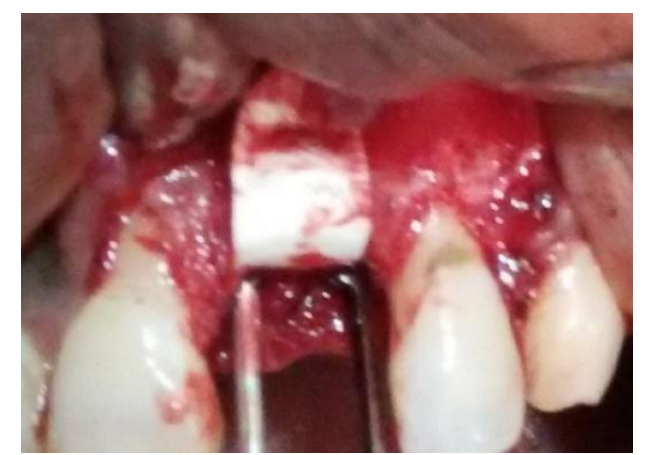

Figure 3:- Allograft being placed

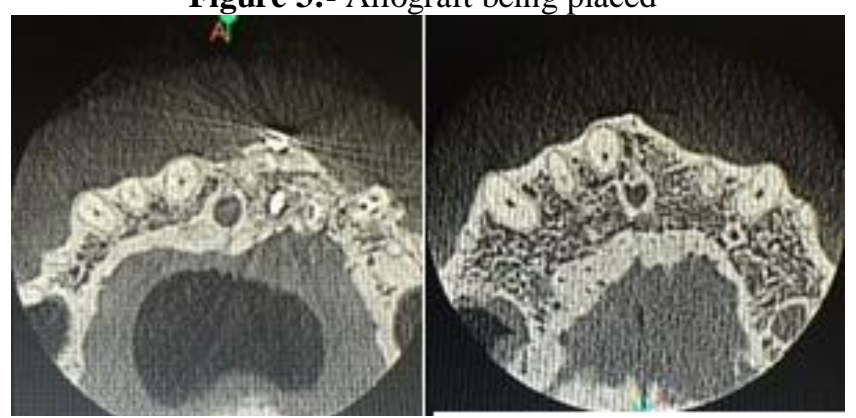

Figure 4:- Adaptation of autograft and Composite graft 
Table 1:- Distribution of subjects according to various parameters.

\begin{tabular}{|c|c|c|c|c|c|c|}
\hline \multirow{3}{*}{\multicolumn{2}{|c|}{ Variables }} & \multicolumn{4}{|c|}{ Group } & \multirow[b]{3}{*}{$\mathrm{p}$ - value } \\
\hline & & \multicolumn{2}{|c|}{ Autogenous graft } & \multicolumn{2}{|c|}{ Composite graft } & \\
\hline & & $\mathrm{N}$ & $\%$ & $\mathrm{~N}$ & $\%$ & \\
\hline \multirow[t]{2}{*}{ Sex } & Female & 1 & 20 & 1 & 20 & \multirow[t]{2}{*}{1} \\
\hline & Male & 4 & 80 & 4 & 80 & \\
\hline \multirow{2}{*}{$\begin{array}{l}\text { Post operative swelling } \\
\text { at recipient site }\end{array}$} & No & 1 & 20 & 4 & 80 & \multirow[t]{2}{*}{0.072} \\
\hline & Mild & 4 & 80 & 1 & 20 & \\
\hline \multirow{3}{*}{$\begin{array}{c}\text { Post operative swelling } \\
\text { at donor site }\end{array}$} & No & 0 & 0 & 4 & 80 & \multirow[t]{3}{*}{$0.011 *$} \\
\hline & Mild & 2 & 40 & 1 & 20 & \\
\hline & Moderate & 3 & 60 & 0 & 0 & \\
\hline \multirow{2}{*}{$\begin{array}{c}\text { Post } \\
\text { operativeparasthesia at } \\
\text { donor site }\end{array}$} & Absent & 4 & 80 & 5 & 100 & \multirow[t]{2}{*}{0.317} \\
\hline & Present & 1 & 20 & 0 & 0 & \\
\hline \multirow[t]{2}{*}{ Pain at donor site } & Absent & 3 & 60 & 5 & 100 & \multirow[t]{2}{*}{0.134} \\
\hline & Present & 2 & 40 & 0 & 0 & \\
\hline
\end{tabular}

Table 2:- Clinical and Radiographic parameters.

\begin{tabular}{|c|c|c|c|c|c|}
\hline \multirow[t]{3}{*}{ Variable } & \multicolumn{4}{|c|}{ Group } & \multirow[t]{3}{*}{$P$ - value } \\
\hline & \multicolumn{2}{|c|}{ Group A } & \multicolumn{2}{|c|}{ Group B } & \\
\hline & Mean & SD & Mean & $\mathrm{SD}$ & \\
\hline \multicolumn{6}{|c|}{ Pre operative bone } \\
\hline Clinical & 2.6 & 0.54 & 2.6 & 0.54 & 1.00 \\
\hline Radiograph & 2.2 & 0.44 & 2.2 & 0.44 & 1.00 \\
\hline \multicolumn{6}{|c|}{ Post operative bone } \\
\hline Clinical & 8.8 & 1.09 & 7.2 & 1.09 & $0.05^{*}$ \\
\hline Radiograph & 8.8 & 1.09 & 6.8 & 1.09 & $0.02 *$ \\
\hline
\end{tabular}

Table 3:- Distribution of subjects according to age and initial torque.

\begin{tabular}{|c|c|c|c|c|c|}
\hline \multirow{2}{*}{ Variable } & \multicolumn{4}{|c|}{ Group } & \multirow{2}{*}{ P - value } \\
\cline { 2 - 5 } & \multicolumn{2}{|c|}{ Autogenous graft } & Composite graft & \\
\cline { 2 - 5 } & Mean & SD & Mean & SD & 0.859 \\
\hline Age (Years) & 27.8 & 3.34 & 28.2 & 3.56 & $0.02 *$ \\
\hline Initial torque (N-Cm) & 38 & 2.73 & 33 & 2.73 & 0 \\
\hline
\end{tabular}

$* \mathrm{P}<0.05$

\section{Discussion:-}

The bone substitute needed for each bone regeneration procedure must be designated based on the individual's characteristics, and the surgical procedure itself. Features such as the osteogenic potential of the host residual bone, systemic condition of subjects and morphology of the defects, will delimit the ideal bone substitute for each situation.In maxilla, centripetal pattern of alveolar resorption, pneumatization of maxillary sinuses, presence of nasal fossae and nasopalatal duct, poor bone quality (D3) complicate implant placement. ${ }^{6}$

There are several methods available to augment the atrophic maxilla, including onlay bone grafting, sinus/nasal bone grafting, guided bone regeneration, interpositional grafting, ridge splitting, and distraction osteogenesis. The choice of a particular technique depends on the need for horizontal or vertical augmentation, degree of atrophy, type of prosthesis, and clinician or patient preference. Autogenous bone grafting offers a well-proven predictable method for ridge augmentation and defect repair for dental implant placement. There are several advantages of using autogenous bone grafts. 7,8

Autogenous graft obtained can either be from intraoral sites or extraorally. Intraoral sites include chin, ramus of the mandible, maxillary tuberosity, anterior nasal spine, alveolar ridge, tori etc which can provide upto3-11cc of bone volume. Extraoral sites include iliac crest, fibula, tibia etc and provides upto bone volume of $25-150 \mathrm{cc} .{ }^{7,9} \mathrm{Composite}$ 
graft can be obtained by combination of autogenous graft harvested from any intraoral or extraoral site combining it with Bio-oss and Biomembrane.

The structure of the bone harvested affects how the graft will incorporate into therecipient site. Cortical block grafts heal through creeping substitution which means once the graftis fixed to the site, osteoclasts begin to resorb the graft material through existingharversian systems which allows ingrowth of fibrovascular tissue and thesecretion of osteoid by osteoblasts. Unlike cortical block grafts, particulate grafts begin with apposition of osteoidand fibrovascular ingrowth through the existing particulate scaffold. Apposition is thenfollowed by resorption and replacement of graft material by more organized lamellarbone. Due to increased vascularization, particulate grafts have greater resorption of the transfer bone and a larger percentage of newly formed bone in comparison withcortical grafts. ${ }^{9}$ this is in conjunction with the findings of the present study. In group B when particulate composite graft was used the amount of resorption of the graft was more as compared to group A.

Mish CM etal stated advantages of the symphysis graft compared with other bone regenerative methods for implant placement in maxillary alveolar defects and a superior quality of bone was found with shorter healing period. Easy access, availability of greater quantities of bone over other intraoral donor sites, low morbidity, no hospitalization, minimal discomfort, no alteration in ambulation and no cutaneous scar. ${ }^{8,10}$

However there are few limitations and difficulties which the subject may encounter, as stated by Jaime Claveroetal ${ }^{11}$ i.e. stiffness and limited mobilization of the vestibule inthe anterior mandibular area during the postoperative period. Some subjects also complained of numbness in the anteriormandibular incisors and canines and decreased sensitivityin the innervation area of the terminal mentalnerve branches.

YildirimM etal ${ }^{12}$ stated that augmentation using a mixture of Bio-Oss and bone harvested intraorally from the mandibular symphysis, retromolar space, or the tuberosity region and concluded that the combination of osteoconductive Bio-Oss and osteoinductive autogenous bone thus proved to be a material suitable for augmentation.

Grafts harvested from membranous bone show less resorption than endochondral bone grafts. Furthermore, membranous cortical grafts revascularization is more rapid than endochondral bone grafts. Therefore, embryological origin of donor bone is important factor for a successful recovery period. ${ }^{13,14,15}$

Hising $\mathrm{P}$ etal ${ }^{16}$ stated that from the time of implant placement and irrespective of loading time, a survival rate of $80.5 \%$ for the individual implants was estimated. In most patients (73\%), Bio-Oss was mixed with autogenous bone from the chin. However, the results indicated that autogenous bone may be excluded from the Bio-Oss graft.

Healing of bone grafts takes place by either of the biological process known as osteogenesis, osteoconduction and osteoinduction. Autogenous bone grafts take up by osteogenesis, osteoconduction and osteoinductionwhile alloplast is taken up by osteoconduction. ${ }^{9}$

In either of the cases postoperative healing of soft and hard tissue was uneventfully. Both autograft and composite graft are equally effective with no significant donor site morbidity. ${ }^{17}$ However, autograft has an edge over composite graft in providing adequate amount of bone.

\section{Conclusion:-}

Dental implants being the most preferred option, has enhanced the usage of bone grafts and its substitutes.Both grafts were ideal in obtaining adequate bone volume, however the autogenous graft provided more bone volume. To conclude a combination of autograft and allograft (composite graft) gives adequate bulk of graft required and larger sample size and follow up is required.

\section{Conflict of Interest:- None declared}

Patient consent:- Informed and written consent taken Institutional ethical board committee clearance obtained. 


\section{Acknowledgements:-}

would like to thank Dr.Anisha and Dr. Sasank for their general support and assistance.

\section{References:-}

1. Brinemark P-I, Adell R, Albrektsson T, et al. An experimental and clinical study of osseointegrated implants penetrating the nasal cavity and maxillary sinus. J Oral MaxillofacSurg 1984; 42:497-505.

2. Lidstrom RD, Symington JM. Osseointegrated dental implants in conjunction with bone grafts. Int J Oral MaxillofacSurg 1988; 47:116-118.

3. Nicholas Toscano, Nicholas Shumaker, Dan Holtzclaw. The Art of Block Grafting A Review of the Surgical Protocol for Reconstruction of alveolar Ridge Deficiency.J Implant AdvClin Dent. 2010;2:2.

4. Jensen OT, Greer R: Immediate placement of osseointegrating implants into the maxillary sinus augmented with mineralized cancellous allograft and Gore-Tex: Second-stage surgical and histologic findings, in Laney WR, Tolman DE (eds): Tissue Integration in Oral OrthMaxillo Recon. 1992; 322.

5. Banwart JC, Asher MA, Hassanein. Iliac crest bone graft harvest donor site morbidity: a statistical evaluation. Spine. 1995;20: 1055-1060.

6. Sorni Marco, Guarinos Juan et al (2005) Implant rehabilitation of the atrophic upper jaw: a review of the literature since 1999. Med Oral Patol Oral Cir Bucal 10:E45-E56.

7. Misch CM. Autogenous bone grafting for dental implants. In: Fonseca RJ, Turvery TA, Marciani RD, editors. 2nd edition. Oral and maxillofacial surgery, vol. 1. Philadelphia: W.B. Saunders Co; 2008. p. 344-70. Chapter 24.

8. Misch CM, Misch CE, Resnik RR, Ismail YH.Reconstruction of maxillary alveolar defects with mandibular symphysis grafts for dental implants: a preliminary procedural report.Int J Oral Maxillofac Implants. 1992 ;7(3):360-6

9. Harry Dym, David Huang, Avichai Stern Alveolar Bone Grafting and Reconstruction Procedures Prior to Implant Placement. Dent Clin N Am. 2012;56:209-218.

10. Zouhary K. Bone graft harvesting from distant sites: concepts and techniques.OralMaxillofacSurgClin North Am 2010;22(3):301-14.

11. Jaime Clavero, Stefan Lundgren, Ramus or Chin Grafts for Maxillary Sinus Inlay and Local Onlay Augmentation: Comparison of Donor Site Morbidity and Complications. Clin Implant Dent Rel Res, 2003; 5, 3.

12. Yildirim M, Spiekermann H, Handt S, Edelhoff D. Maxillary sinus augmentation with the xenograft Bio-Oss and autogenous intraoral bone for qualitative improvement of the implant site: a histologic and histomorphometric clinical study in humans. Int J Oral Maxillo Implants, 2001; 16(1):23-33.

13. Misch CM, Misch CE, Resnik RR. Reconstruction of maxillary alveolar defects with mandibular symphysis grafts for dental implants: A preliminary procedural report. Int J Oral Maxillofac Implants 1992; 7:360,

14. DoganDolanmaz, AlparslanEsen, GulsunYıldırım, and OzgurInan. The use of autogenous mandibular bone block grafts for reconstruction of alveolar defects. AnnMaxillofac Surg. 2015; 5(1): 71-76.

15. Ozaki W, Buchman SR. Volume maintenance of onlay bone grafts in the craniofacial skeleton: Microarchitecture versus embryologic origin. PlastReconstr Surg. 1998;102:291-9

16. Hising P, Bolin A, Branting CThe Private Clinic of Oral and Maxillofacial Surgery.Int J Oral Maxillo Implants 2001; 16(1):90-97.

17. Nicola U. Zitzmann Treatment of Angular Bone Defects with a Composite Bone Grafting Material in Combination with a Collagen Membrane. J Periodontol 2003, Vol. 74, No. 5,687-694. 